\title{
Incidencia de la teología de la liberación en la filosofía latinoamericana
}

\section{Observación preliminar}

Para evitar posibles malentendidos o, más exactamente dicho, para evitar que se asocien falsas expectativas con el título que se ha dado a este punto de nuestro proyecto de investigación*, quiero señalar de entrada que mi presente trabajo, precisamente por saberse parte integrante de dicho proyecto, se limita al estudio de la influencia o incidencia que ha tenido en la filosofía de América Latina la teología de la liberación, en el sentido estricto en que la consideramos en este proyecto, a saber, como articulación explícita y sistemática de una nueva forma de hacer teología en América Latina.

Debo advertir, por otra parte, que si considero necesario hacer de entrada esta observación es porque me parece que no se puede identificar sin más el término "teología de la liberación" con el concepto sistemático de teología o teologías de la liberación que se ha ido perfilando y articulando en América Latina en los últimos 25 años. En primer lugar porque, en su sentido más amplio, "teología de la liberación" en América Latina sobrepasa el marco experiencial de la fe cristiana, sea católica o protestante, para remitirnos también a experiencias liberadoras de fe en tradiciones religiosas no cristianas, tanto en los ámbitos de las religiones indígenas como en el de las afroamericanas'. Y en segundo lugar porque, incluso en el específico ámbito de la fe cristiana, el término "teología de la liberación", puede extenderse igualmente a aquellas formas de teología que no son fruto del "teólogo profesional" sino que se manifiestan tanto en prácticas cristianas de comunidades populares como en expresiones culturales de autores

* El original de este trabajo apareció en alemán como parte integrante de un proyecto de investigación coordinado por el autor. Cfr. Raúl Fornet-Betancourt (ed.), Befreitungstheologie: Kritischer Rückblick und Perspektiven für die Zukunft, 3 tomos, Mainz, 1977. 
latinoamericanos inspirados por la fe cristiana, y para las cuales Pablo Richard ha encontrado el adecuado título de "teologías implícitas"-

En este sentido amplio se puede y, a mi modo de ver, se debe, incluso, hablar en América Latina de una tradición de "teología de la liberación" de carácter interreligioso e interconfesional, que va creciendo, no al margen, sino precisamente en el seno de procesos sociales y culturales de liberación, documentando así la función liberadora del factor religioso en las sociedades y culturas latinoamericanas; y que representa de esta suerte la tradición-memoria en la que de hecho está enraizada la actual teología de la liberación. Ambas son momentos de una misma historia de liberación. Y mucho se podría decir sobre las relaciones que las dos desarrollan en el curso de la dinámica de esa única historia de liberación que escriben los pueblos latinoamericanos, desde la rebelión de Hatuey en Santo Domingo y Cuba, hasta la rebelión indígena de Chiapas.

Pero aquí me interesa resaltar únicamente esto: esa "teología de la liberación" en sentido amplio no es la mera prehistoria de la teología de la liberación explícita que hoy conocemos justamente con ese nombre. Es, más bien, como acabo de decir, la tradición que permite que el comienzo de la actual teología de la liberación se reconozca como parte de una memoria originaria de liberación. Y si recalco sólo este aspecto, es porque me interesa ahora dejar claro que, desde esta perspectiva, "teología de la liberación" no nace en América Latina con los trabajos, pongamos por caso, de Alves", Assmann ${ }^{4}$ o Gutiérrez ${ }^{5}$.

Y esto, por su parte debe ser, en el marco del presente trabajo, tanto más subrayando cuanto que aquí nos limitamos conscientemente justo a la teología de la liberación que se articula y sistematiza en forma explícita como tal teología. O sea que la limitación no se debe a que se parta del supuesto de que "teología de la liberación" es sólo la que emerge con tal nombre a partir de 1968/69, sino que se debe más bien a la simple razón de que es esta forma explícita "profesional" de la teología de la liberación la que es objeto de estudio en este proyecto de investigación.

Aclarado lo anterior, precisamos entonces el cometido de este trabajo de la manera siguiente: se tratará de hacer un balance de la incidencia que haya podido tener la teología de la liberación explícita y "profesional" en el desarrollo de la filosofía en América Latina a partir de 1968/69. Y se tratará, además, de establecer, sobre la base de los resultados de la evaluación anterior, los puntos fundamentales para la agenda de un diálogo más intenso y fecundo entre teología de la liberación y filosofía en América Latina. Estos dos cometidos son los que intentaré realizar en los dos apartados que componen el presente trabajo. 


\section{Hacia un balance de la incidencia de la teología de la liberación en la filosofía en América Latina}

Cualquier intento de balance o revisión de la influencia que haya podido ejercer la teología da la liberación en el desarrollo de la filosofía en América Latina a partir de 1968/69, habrá de tener en cuenta, a mi parecer, de entrada, dos momentos de muy especial carácter que se refieren a los específicos procesos particulares que la filosofía y la teología van cumpliendo por separado en América Latina en estos años y que configuran así el trasfondo de historia de las ideas, a cuya luz hay que ver su compleja y muchas veces sólo implícita relación en los últimos veinticinco años.

Estos dos momentos son los siguientes: Por parte de la filosofía, se trata del hecho de que, justo en los años en que la teología de la liberación va alcanzando su primera articulación explícita y se hace pública como corriente que puede incidir en otras formas del saber, la filosofía en América Latina retoma con inédito vigor una vieja cuestión pendiente en su historia específica, a saber, la cuestión de la constitución y fundamentación de una "filosofía americana", entendiendo por ésta una filosofía contextualizada en la realidad social, cultural, política e histórica de los países latinoamericanos. Como se sabe, esta cuestión quedó abierta en la historia de la filosofía latinoamericana prácticamente desde la fecha en que se planteó por primera vez, entre los años de 1837 y 1842 por el pensador argentino Juan Bautista Alberdi (1810-1887), en el sentido estricto de un programa para redefinir toda la creación filosófica desde la situación histórica de nuestros países.

He aquí un pasaje decisivo en el programa de esa "filosofía americana" visualizada por Alberdi: "Nuestra filosofía, pues, ha de salir de nuestras necesidades. Pues según estas necesidades; ¿cuáles son los problemas que la América está llamada a establecer y a resolver en estos momentos? Son los de la libertad, de los derechos y goces sociales de que el hombre puede disfrutar en el más alto grado en el orden social y político... De aquí es que la filosofía americana debe ser esencialmente política y social en su objeto; ardiente y profética en sus instintos; sintética y orgánica en su método; positiva y realista en sus procederes; republicana en su espíritu y destinos. Hemos nombrado la filosofía americana y es preciso que hagamos ver que ella puede existir... Americana será la que resuelva el problema de los destinos americanos"'.

Pero hay que saber también que, precisamente porque se trata de una cuestión que queda abierta desde su planteamiento inicial, esta cuestión por la "filosofía americana" no se replantea solamente en el contexto histórico aludido de los finales de los años sesenta, sino que es retomada una y otra vez por filósofos latinoamericanos. Y por eso he dicho antes que en 1968/69 se replantea con "inédito vigor". Y quiero insistir en esto porque no debe tenerse la impresión de que esta cuestión se olvida hasta dicha fecha. No, no es ese el caso. Pues, por 
poner ahora sólo unos pocos ejemplos, se replantea en los años 20 en el contexto del debate en tomo a la pregunta por la existencia o no de un pensamiento iberoamericano ${ }^{7}$; y reaparece en forma de un movimiento de significación continental y coordinada en la década de los años 40 con trabajos como los de Ardao, Frondizi, Gaos o Zea ; para ser replanteada de nuevo en los años 50 como una preocupación continental digna de ser elevada a punto de debate en foros internacionales tales como el "III Congreso Interamericano de Filosofía", celebrado en México en 1950; o las "Conversaciones Filosóficas Interamericanas", que tuvieron lugar en La Habana ese mismo año; que entre sus temas centrales de debate tuvieron precisamente la cuestión de la "filosofía americana"."

Estos escasos ejemplos ilustran pues que el replanteamiento de la cuestión por la "filosofía americana" acontece en el marco de una tradición de pensamiento que, aunque no haya podido cristalizar una perspectiva de acceso o abordaje definitivo de dicha cuestión, sí crea, sin embargo, las condiciones para que su reformulación en 1968/69 marque un giro en la historia de la cuestión por la "filosofía americana"; un giro que, al mismo tiempo que culmina la tradición que lo posibilita, representa el comienzo de una nueva manera de enfocar la posible respuesta a la cuestión por la "filosofía americana". Este giro marca, si se quiere, el comienzo de una nueva tradición al interior de la historia de la pregunta por una "filosofía americana", por cuanto que es este giro de los años 1968/69 el que posibilita por su parte que esta pregunta se vaya perfilando en su articulación y formulación en los términos de la pregunta por la filosofía de la liberación latinoamericana. Se trata entonces del giro que hace posible el paso de la "filosofía americana" a la "filosofía de la liberación". Por esta razón, hablo del replanteamiento de esta cuestión en 1968/69 como de un acontecimiento que le imprime un "inédito vigor". Pero ¿en qué consiste la novedad de este replanteamiento de la cuestión por la "filosofía americana"?

Según el filósofo peruano Augusto Salazar Bondy (1925-1974), quien, en mi opinión, debe ser considerado como el verdadero promotor de este cambio de perspectiva, el debate o la cuestión por la "filosofía americana" tiene que ser planteado como pregunta por la calidad de autenticidad de la filosofía en los países latinoamericanos. Pero preguntar por la autenticidad de la filosofía en América Latina significa, para Salazar Bondy, plantear una cuestión que sobrepasa los límites de la filosofía; ya que, si filosofía es también una forma de expresión cultural o una forma racional que crece en una cultura, es lógico entonces que el contexto mayor del debate por la "filosofía americana" como forma auténtica de reflexión filosófica no puede ser otro que la misma cultura latinoamericana.

Desde esta óptica, pues, la novedad del replanteamiento de la cuestión por la "filosofía americana" radica en resituar la pregunta entroncándola con la problemática de la situación de la cultura en general. Salazar Bondy resume este giro en el planteamiento de la cuestión al constatar que "las insuficiencias y debilida- 
des de nuestra filosofía no son rasgos negativos de la filosofía tomada separadamente, sino resultado de un problema más hondo y fundamental que afecta a nuestra cultura en conjunto"."'

Para comprender esta constatación en la que Salazar Bondy radicaliza la cuestión por la autenticidad de la filosofía en América Latina al interpretarla como un problema que refleja el problema de fondo de la cultura de los países latinoamericanos, hay que tener presente que el autor peruano apoya dicha constatación en su diagnóstico de la llamada cultura latinoamericana como un producto malogrado; es decir, que se trata de una cultura enajenada, mistificada; de una cultura reproductora de inautenticidad, porque está impregnada y determinada por patrones ideológicos y valorativos ajenos a las verdaderas necesidades y aspiraciones de los pueblos latinoamericanos.

Pero porque, por otra parte, la cultura para Salazar Bondy no es una entidad abstracta, desligada de las instituciones sociales ni de la organización económica ni de la estructuración político-estatal de las sociedades humanas, la novedad de conectar la problemática de la "filosofía americana" con la más general de la "cultura latinoamericana" implica asimismo vincular la cuestión de la inautenticidad de la filosofía y/o de la cultura con la realidad histórica concreta de la situación económica, política y social de América Latina. Y, característico de esta vinculación que establece Salazar Bondy entre inautenticidad filosófica y/o cultural y situación político-económica, es que para él esta realidad histórica —que interpreta precisamente en términos de subdesarrollo y dominación" - es, en última instancia, la raíz o causa de la inautenticidad cultural o filosófica. O sea, que la inautenticidad de la cultura y de la filosofía en América Latina reflejarían la situación de subdesarrollo de los países latinoamericanos; y esto, por cierto, en el sentido de una deformación resultante de un largo proceso histórico de colonialismo, dependencia y dominación. De aquí que Salazar Bondy precise su diagnóstico de la cultura latinoamericana como cultura inauténtica en el sentido exacto de una "cultura de la dominación", y nos diga: "Por tanto, hablar de la cultura de la dominación es hablar no sólo de las ideas, las actividades y los valores que orientan la vida de los pueblos, sino también de los sistemas que encuadran su vida y no la dejan expandirse y dar frutos cabales"12.

Significativo para caracterizar la novedad en el cambio de perspectiva que promueve Salazar Bondy en el planteamiento de la pregunta por la "filosofía americana" es, además, que su diagnóstico de la cultura latinoamericana como una "cultura de la dominación" va acompañado del esbozo de una alternativa histórico-política que él mismo resumió en el programa de luchar por la creación de una "cultura de la liberación" sobre la base de la cancelación real de la situación de subdesarrollo ${ }^{13}$.

De esta suerte, Salazar Bondy sienta las bases, en efecto, para que la pregunta por la "filosofía americana" no solamente se agudice en la cuestión por la 
autenticidad en un sentido cultural abstracto sino también como pregunta por una nueva forma de hacer filosofía. Desde la óptica de Salazar Bondy, la pregunta por la "filosofía americana" no puede ser planteada más que en estos términos concretos: ¿Cómo es posible hacer filosofía auténticamente en medio de una cultura de la dominación? Y es evidente que, con este nuevo planteamiento de la cuestión, Salazar Bondy está buscando en el fondo la viabilidad histórico-real de una reflexión filosófica que sepa dar cuenta de la realidad de los países latinoamericanos.

Por eso, su cambio de perspectiva no lo lleva únicamente a la denuncia del pensamiento latinoamericano como inauténtico: “...el pensamiento hispanoamericano ha obedecido de hecho a motivaciones distintas a las de nuestro hombre y ha asumido intereses vitales y metas que corresponden a otras comunidades históricas. Ha sido una novela plagiada y no la crónica verídica de nuestra aventura humana"14. Ese cambio de perspectiva en la forma de plantear la pregunta significa además, y sobre todo, un esfuerzo por transformar positivamente la filosofía en América Latina; un esfuerzo que Salazar Bondy plantea ya explícitamente como programa de una nueva filosofía: "...la filosofía que hay que construir no puede ser una variante de ninguna de las concepciones del mundo que corresponden a los centros de poder de hoy, ligadas como están a los intereses y metas de esas potencias. Al lado de las filosofías vinculadas con los grandes bloques actuales o del futuro inmediato es preciso, pues, forjar un pensamiento que, a la vez que arraigue en la realidad histórico-social de nuestras comunidades y traduzca sus necesidades y metas, sirva como medio para cancelar el subdesarollo y la dominación que tipifican nuestra condición histórica"15.

$Y$, en el fondo, es este esbozo de programa de una nueva filosofía lo verdaderamente definitivo en el replanteamiento que hace Salazar Bondy de la cuestión por la "filosofía americana". Dicho en otros términos, su replanteamiento de la cuestión es apertura de una alternativa histórica para la filosofía en América Latina: "El problema de nuestra filosofía es la inautenticidad. La inautenticidad se enraíza en nuestra condición histórica de países subdesarrollados y dominados. La superación de la filosofía está, así, íntimamente ligada a la superación del subdesarrollo y la dominación, de tal manera que si puede haber una filosofía auténtica ella ha de ser fruto de este cambio histórico trascendental. Pero no necesita esperarlo; no tiene por qué ser sólo un pensamiento que sanciona y corona los hechos consumados. Puede ganar su autenticidad como parte del movimiento de superación de nuestra negatividad histórica, asumiéndola y esforzándose en cancelar sus raíces"'n.

Salazar Bondy da así la clave para poder hacer filosofía auténtica en las condiciones adversas que impone una cultura de la dominación. Y se entiende que esa clave es la de transformar la reflexión filosófica en parte integrante del proceso global de liberación histórica. Por eso habla de esa filosofía en términos de una filosofía que se convierte en "conciencia lúcida de nuestra condición 
deprimida como pueblos"17 y que, a través en buena parte de una tarea destructiva y autocrítica, se configura positivamente como "conciencia liberadora"'s.

En resumen, pues, lo que propone Salazar Bondy es transformar la "filosofía latinoamericana" en parte de una "cultura de la liberación"1".

Creemos entonces que la novedad en la reformulación que hace Salazar Bondy del problema de la filosofía latinoamericana radica, en último término, en que esboza la perspectiva para que la filosofía en América Latina tome el rumbo de la filosofía de la liberación. Así, sin usar todavía el término expreso de "filosofía de la liberación" —esta expresión la usará sólo en 1973 en su ponencia en las "Cuartas jornadas académicas de las Facultades de Filosofía y Teología", en San Miguel, Argentina ${ }^{211}$ - Salazar Bondy esboza esta perspectiva de manera clara ya desde 1968; pues, además de lo ya señalado, advirtió también lo siguiente: "Pero hay todavía posibilidad de liberación y, en la medida en que la hay, estamos obligados a optar decididamente por una línea de acción que materialice esa posibilidad y que evite su frustración. La filosofía hispanoamericana tiene también por delante esta opción de la que, además, depende su propia constitución como pensamiento auténtico".21

Para ejemplificar el cambio de perspectiva que se opera en 1968/69 en la filosofía latinoamericana, he mencionado hasta ahora sólo el nombre de Salazar Bondy. Y esto no carece de fundamento; pues, como ya indiqué, él es el verdadero iniciador de este cambio. Con todo, quiero señalar que el impulso de Salazar Bondy recibió en 1969 un apoyo decisivo con la perspectiva complementaria que desarrolló Leopoldo Zea (México, 1912), precisamente conectando con la tesis central defendida por Salazar Bondy en su libro ¿Existe una filosofía de nuestra América? Se recordará, en efecto, que en 1969, Leopoldo Zea publica en México su ensayo La filosofía americana como filosofía sin más, donde presenta lo que se podría llamar la otra cara complementaria del giro que propone Salazar Bondy en la filosofía latinoamericana. Pues Zea, retomando sus ideas y su línea de trabajo expuestas ya desde 1942, insistirá en que la autenticidad de la filosofía en América Latina no es una posibilidad a conquistar sino una realidad presente; es decir, que la filosofía en América Latina conoce autenticidad en su historia ya escrita porque ésta es también la historia de pensadores que han intentado dar cuenta de nuestra realidad. Por ello, Zea subraya frente a Salazar Bondy que, sin negar las posibles consecuencias de la situación del subdesarrollo para el ejercicio de la filosofía, lo decisivo está en saber rescatar esa tradición auténtica; en descubrirla como una actitud frente a la realidad; y, entroncando con ella, comprender que la autenticidad de la filosofía actual en América Latina "vendrá de nuestra capacidad para enfrentarnos a los problemas que se nos plantean hasta sus últimas raíces, tratando de dar a los mismos la solución que se acerque más a la posibilidad de la realización del nuevo hombre"’-2. Y, en acuerdo con Salazar Bondy, precisa Zea que filosofía americana auténtica es la que 
haga consciente nuestro subdesarrollo y señala las posibilidades de su vencimiento y la forma como vencerlo"23. De esta forma, termina Zea, en convergencia con Salazar Bondy, afirmando la necesidad de concretizar la autenticidad de la filosofía en América Latina en una "filosofía de la acción encaminada a subvertir, a cambiar un orden en el que la auténtica esencia del hombre ha sido menoscabada"24. Sólo que, a diferencia del diagnóstico de Salazar Bondy sobre el pasado filosófico de América Latina —como se insinuaba antes-Zea insiste, respaldado en su profundo conocimiento de la historia de las ideas filosóficas en el subcontinente, en que esa filosofía crítica y auténtica no es una tarea del futuro inmediato ni un programa que se acaba de lanzar sino toda una línea de tradición en la historia de la filosofía latinoamericana, a saber, la línea de pensamiento mantenida y continuada por los emancipadores mentales de nuestra América, desde Andrés Bello hasta Frantz Fanon, pasando por José Martí. Para Zea, sin embargo, esa filosofía auténtica se caracterizará por ser "no ya sólo una filosofía de nuestra América y para nuestra América, sino filosofía sin más del hombre y para el hombre en donde quiera que este se encuentre"25. Y, de esta suerte, la filosofía latinoamericana auténtica será lo que es toda filosofía auténtica en cualquier parte del mundo, a saber: reflexión liberadora para el hombre negado por mecanismos de dominación.

En este contexto hay que advertir que, como Salazar Bondy, Zea no habla de "filosofía de la liberación", sino hasta 1973, justo en el marco de las citadas Jornadas de San Miguel ${ }^{26}$. Pero su obra citada de 1969 tiene que ser vista como un complemento necesario a la perspectiva abierta por Salazar Bondy; es decir que, a pesar de la diferencia de detalle que acentúa Zea frente a Salazar Bondy, su libro La filosofía americana como filosofía sin más es un apoyo decisivo a la empresa de transformación de la "filosofía latinoamericana" en una nueva filosofía de la liberación.

Retengamos entonces que en $1968 / 69$, con los aportes, sobre todo de Salazar Bondy y de Zea, la filosofía en América Latina ha emprendido una tarea de revisión y de reubicación histórico-teórica que apunta con toda claridad a la resolución de la vieja cuestión en tomo a la autenticidad de la filosofía latinoamericana con el programa de constitución de una filosofía de la liberación. Y, sin embargo - es conveniente añadir esto para redondear este proceso-, no son ni Salazar Bondy ni Zea los primeros en usar ese nuevo titulo; pues, como ya he dicho, lo usan sólo en 1973. Pero ya dos años antes Enrique Dussel recogía esta tradición y la orientaba definitivamente por la línea de una filosofía de la liberación en sentido explícito. Pues, como es sabido, en el II Congreso Nacional de Filosofía Argentina, celebrado en 1971 en Córdoba, Dussel presentó una ponencia titulada Metafisica del sujeto y liberación en la que $-\mathrm{y}$ esto me parece decisivo-, recogiendo la preocupación de Salazar Bondy, responde precisamente a la pregunta de la autenticidad de la filosofía en América Latina con la alternativa de una filosofía crítica de la liberación ${ }^{27}$. 
Mas dejemos a un lado la cuestión implicada en mi última observación, es decir, la de la "paternidad" de la filosofía de la liberación, para resaltar lo único que interesa en el contexto de este trabajo: a partir de los años 1968/69 la filosofía latinoamericana entra en un nuevo proceso de transformación que, precisamente porque connota, entre otras cosas, la contextualización de la reflexión filosófica, la prepara para una positiva influencia de la teología de la liberación sobre ella.

El segundo momento a que me quiero referir tiene que ver con el desarrollo de la teología en esta época inicial. Es obvio que no puedo pretender reconstruir aquí las condiciones sociales, eclesiales, teóricas, etc.; que posibilitan la gestación articulada de la teología de la liberación en América Latina ${ }^{28}$. Y es que, además, tampoco se trata aquí de eso. Lo que me interesa subrayar ahora, por parte de la teología en América Latina, es que, al menos en lo que atañe a las condiciones filosóficas que directa o indirectamente ayudan a preparar su formulación en términos de teología de la liberación $-y$ que son las que quiero mencionar aquí-, ella recorre, por decirlo así, el camino inverso a la filosofía.

Se observará en efecto que, mientras la filosofía latinoamericana busca su transformación a través de la recuperación de su propia tradición crítica para acreditarse así justamente como filosofía latinoamericana auténtica, la teología en América Latina parece orientarse en estos años mas bien en el pensamiento crítico europeo y norteamericano. O sea que, curiosamente, prepara las condiciones para su formulación como teología de la liberación de espaldas al proceso que va cumpliendo la filosofía en el subcontinente. Esto se puede comprobar en base tanto a la citada tesis de R. Alves como al también citado libro de G. Gutiérrez; obras pioneras en la articulación de la teología (profesional) de la liberación, pero que demuestran que el interlocutor teórico privilegiado es el pensamiento europeo y norteamericano avanzado, y no la propia tradición cultu$\mathrm{ral}^{24}$. Y, en este sentido, creo que hay que reconocer como justificada la crítica que le hacía Jürgen Moltmann al libro de Gutiérrez, cuando señalaba lo siguiente: "La Teología de la liberación de Gustavo Gutiérrez (traducida al alemán en 1973) es considerada por teólogos latinoamericanos y europeos frecuentemente como la primera teología escrita desde una perspectiva latinoamericana. Y el lector espera descubrir a América Latina en este libro. El libro es extraordinario, pero en este punto decepciona. Gutiérrez presenta el proceso de liberación en América Latina como un repaso de la historia europea de la libertad. Uno se entera de esta historia de la libertad, en cuanto que se le ilustra sobre Kant y Hegel, Rousseau y Feuerbach, Marx y Freud. El "proceso de secularización" se analiza en detalle en base a Gogarten, Bonhöffer, Cox y Metz. Todo esto se trabaja con originalidad y ofrece nuevos conocimientos - pero precisamente sólo en la historia de Europa, y apenas en la de América Latina" ${ }^{\text {"31". }}$ 
Es cierto, por otro lado, que la teología de la liberación inicial, como bien ha señalado Juan Luis Segundo, “... nació de una pastoral, es decir, no nació de una teoría ni se hizo en un laboratorio: nació de una necesidad concreta, la de dar un respaldo teológico, cristiano, a los cristianos que se comprometían: era necesario acompañarlos, iluminar su acción..." explicando Segundo, ese "condicionamiento pastoral sometió a la teología de la liberación a lo que yo llamaría una doble prisa o urgencia: la primera teología de la liberación fue una especie de teología urgente. (...) Parecía, pues, urgente optar y actuar, sin tiempo para reflexiones teológicas o ideológicas previas y que fueran a largo plazo"32.

Pienso, sin embargo, que ante la deficiencia que pone en evidencia la observación crítica de Moltmann, ese "condicionamiento pastoral" de la primera teología de la liberación tiene que ser relativizado en su importancia. En todo caso, no puede servir de argumento para explicar la falta de referencia sistemática a la tradición cultural, y en especial a la filosófica, de América Latina. Pues, aún reconociendo como un hecho el "condicionamiento pastoral" apuntado por Segundo, no se puede negar que la primera teología de la liberación es todo, menos una teología "inculta". O sea, que lo que se le puede reprochar no es que haya investigado poco, sino que lo ha hecho unilateralmente, en cuanto que es teología - como lo prueban las obras de Alves y de Gutiérrez, entre otros- que documenta sólidamente sus críticas y perspectivas, pero recurriendo con preferencia muy decidida a la tradición critica del pensamiento europeo y norteamericano; y esto, precisamente, al precio de un notorio descuido de la tradición latinoamericana.

Por eso, la deficiencia evidenciada en la crítica de Moltmann se explicaría, a mi entender, menos por el "condicionamiento pastoral", y más por lo que llamaría el "condicionamiento cultural-académico" de los teólogos latinoamericanos protagonistas de la primera teología latinoamericana (Alves, Assmann, Segundo, Gutiérrez, etc.). La expresión "condicionamiento cultural-académico" quiere decir aquí que se trata de autores que no solamente se forman en Europa o Norteamérica sino que, además, han recibido en América Latina una formación filosófico-teológica de claro carte eurocéntrico donde la temática de las tradiciones culturales latinoamericanas brillaba por su ausencia. No olvidemos que, precisamente por el dominio total de planes de estudios eurocéntricos y, peor aún, romanos, cursos tales como historia de las ideas en América Latina o historia de la teología latinoamericana eran en aquellos años absolutamente desconocidos en los centros eclesiásticos de formación.

Así, ese "condicionamiento cultural-académico" predisponía a investigar con más cuidado las ideas de un Blondel, Bloch, Congar, Marcuse o Rahner; que a estudiar a un Guamán Poma de Ayala, un Francisco de Paula y Vigil, a un José Martí o el nuevo planteamiento filosófico de Salazar Bondy o Zea. Diría incluso 
-acaso con cierto tono polémico— que, más que urgencia pastoral, lo que hay es simple y llanamente ignorancia de lo propio ${ }^{33}$ en este terreno de historia de las ideas $\mathrm{y}$, concretamente, de las ideas filosóficas.

Mas, por otra parte, creo que hay también lo que se podría llamar la opción de la primera teología de la liberación contra la filosofía; o, dicho en términos más positivos, a favor de buscar sus mediaciones teóricas en las ciencias sociales, y no en la filosofía. Así, por ejemplo, escribía Hugo Assmann: “...la señal distintiva de la teologia — su referencia a la fe y sus testimonios históricos- no basta en sí misma para distinguir una buena teología de otra menos buena. Esta distinción requiere que, además de la nota distintiva y caracterizante de la teología, se tengan en cuenta criterios de validez histórica de la praxis, como praxis liberadora, que implican el recurso a las ciencias humanas. La evangelización, al servicio de la cual está puesta la teología, evidentemente quiere ser articulación histórica del amor-praxis, y no simple enunciación de un mensaje... Por lo tanto en su tarea global, la teología se ve necesariamente dirigida a las ciencias humanas, incluso para poder determinar aquello que la distingue de las mismas". ${ }^{34} \mathrm{Y}$, por su parte, Roberto Oliveros constataba: "Hugo Assmann y Gustavo Gutiérrez superan la exclusividad de la filosofía como base de racionalidad de la teología. La adopción de los avances de las ciencias y de su vocabulario, se abre paso en la teología latinoamericana".35.

$\mathrm{Y}$ en este recurso a las ciencias sociales -que va a constituir sin duda una de las grandes novedades metodológicas que hoy agradecemos a la teología de la liberación- sí se da un entronque directo con una tradición de pensamiento latinoamericano, a saber, el pensamiento social-económico que se condensará especialmente a partir de la década de los años sesenta en la sociología crítica latinoamericana con su núcleo fuerte de la teoría de la dependencia; y cuyos principales representantes (como F.H. Cardoso, E. Faletto, Th. dos Santos, A.G. Frank, O. Sunkel etc.) son cita obligada en los trabajos de la teología de la liberación en toda esta época. Este vínculo estrecho entre la teología de la liberación y la nueva ciencia social latinoamericana debería haber facilitado el diálogo con la filosofía de la liberación en formación de Salazar Bondy y Zea, entre otros; pues tanto filósofos como teólogos estaban recurriendo al nuevo horizonte de comprensión abierto por la teoría de la dependencia. Y, sin embargo, no fue así. En esta primera etapa el recurso a las ciencias sociales parece alcanzar en la teología de la liberación el nivel de una sustitución de la filosofía. Y la conexión que se da con el marxismo no desdice en nada este diagnóstico, pues la vinculación con el marxismo se da precisamente en el contexto del recurso a las ciencias sociales; $y$, por eso, como apoyo puntual en la mediación socioanalítica. ${ }^{36}$

En este sentido, pues, se puede hablar de un desencuentro de la primera teología de la liberación con la filosofía latinoamericana. Dussel pareció intuir este desencuentro, así como las razones que podían llevar a la teología de la 
liberación a mantenerlo, pues ya en 1971 advertía lo siguiente: "La función de la filosofía en el proceso de liberación es insustituible: ninguna ciencia, ninguna praxis podrá jamás reemplazar a la filosofía en su función esclarecedora y fundamental". .7

De acuerdo a lo dicho, tenemos entonces que la teología de la liberación que va a ejercer su influjo sobre la filosofía latinoamericana, es, al menos en su primera formulación, una teología que se articula como teología latinoamericana, sin contar prácticamente con el potencial crítico que la filosofía del subcontinente venía ya preparando y poniendo a punto para su transformación en filosofía de la liberación.

Sobre el trasfondo de estos dos momentos en los que hemos procurado esbozar los grandes rasgos de los procesos paralelos que van cumpliendo la filosofía y la teología en América Latina a finales de los años 60 y principios de los 70 , se ve con claridad que en estos años resurge un tipo de filosofía en América Latina que, debido a la propia dinámica de su nuevo desarrollo, echa las bases para una convergencia objetiva en método y contenidos con la teología de la liberación y que prepara de esta suerte las condiciones teóricas para que ésta última pueda incidir en su desarrollo ulterior. $Y$ es evidente también que ese tipo de filosofía no es otro que el que he venido describiendo como "filosofía latinoamericana-en-paso-hacia-su-constitución-como-filosofía-de-la-liberación".

Por esto, antes de esbozar el balance propiamente dicho de la influencia de la teología de la liberación en la filosofía en América Latina a partir de 1968/69, quiero observar todavía lo siguiente: El hecho de que haya presentado en lo fundamental sólo este tipo o modelo de filosofía no obedece a ninguna decisión arbitraria ni responde tampoco al interés de reducir la filosofía en América Latina a lo que, sobre todo a partir de 1973 , se conocerá como el movimiento de filosofía de la liberación. No hay, pues, ni arbitrariedad ni tampoco ideología en el hecho de privilegiar aquí la línea de la tradición filosófica indicada. Y no hay ni lo uno ni lo otro porque, como mostraré a continuación, es precisamente en este modelo, que se condensará en el complejo movimiento de filosofía de la liberación, en el que se hará sentir, y de manera muy efectiva, la positiva influencia de la teología de la liberación. Paso entonces a documentar mi ensayo de balance.

Pero quiero comenzar, como acabo de insinuar, mostrando que la influencia de la teología de la liberación en la filosofía de América Latina se ejerce de hecho en el ámbito de la corriente de la filosofía de la liberación, y no en ningún otro. Para mostrarlo, ya que es imposible pretender reconstruir aquí la historia de la filosofía en América Latina en sus últimos veinticinco años, recurriré primero a tres ejemplos, esto es, a tres corrientes filosóficas que son especialmente representativas de otros tipos de pensamiento en el desarrollo global de la filosofía en la América Latina de este tiempo: 
- La filosofía cristiana tradicional, que en América Latina se ha mostrado hasta ahora inmune a la influencia de la teología de la liberación. Es más, connotados representantes de esta corriente han rechazado abiertamente el planteamiento de la teología de la liberación por considerarlo una perversión de la esencia del saber filosófico y/o teológico. Los congresos de Filosofía Cristiana en América Latina con la participación rectora de filósofos como Agustín Basave Fernández del Valle, Alberto Caturelli, Octavio Derisi y Stanislas Ladusáns son un buen ejemplo de esta actitud de abierto rechazo e incluso de exclusión ${ }^{38}$.

- La filosofía analítica, que goza de fuerte e influyente tradición en casi todos los países latinoamericanos; pero que ni siquiera en aquellas áreas que, por motivo de su mismo objeto de estudio, tales como la filosofía del derecho o la filosofía política, pueden tender un puente a la perspectiva de la teología de la liberación, se ha dejado impactar por ésta ${ }^{34}$. Y no ha faltado algún representante que ha hecho público su claro desprecio por la teología de la liberación. Así, por ejemplo, Mario Bunge, quien ha dicho que los representantes de la teología de la liberación, "desde el punto de vista filosófico, me parecen oscurantistas"

- La filosofia marxista ortodoxa, que en América Latina también tiene fuerte tradición y que, como en el caso de la filosofía analítica, mantiene una notoria distancia frente a la teología de la liberación; y esto, por cierto, a pesar de que no pocos teólogos de la liberación han contribuido a revitalizar en América Latina la discusión sobre la obra de Marx. Se nota, además, y esta vez paradójicamente en paralelismo con la posición de la filosofía cristiana tradicional, una actitud defensiva que va desde el rechazo abierto hasta el silenciamiento excluyente o la malintencionada interpretación como posición reformista burguesa ${ }^{41}$. Sin que falten, por otra parte, representantes de un marxismo crítico que pongan en duda la posibilidad de que la teología de la liberación pueda aportar algo al marxismo como tal. En este sentido es ilustrativa esta respuesta de Serrano Caldera a la pregunta que se le hacía al respecto: "No sé si se trata de un aporte al marxismo que es una teoría que tiene categorías y métodos propios... Pero hay un aporte al proceso revolucionario en América Latina, un aporte que es fundamentalmente ético-social... El aporte de la teología de la liberación y la participación de los cristianos han sido decisivos en los procesos de liberación. Sin embargo, no me atrevería a decir cuál ha sido la influencia que el pensamiento religioso haya podido ejercer en el interior del pensamiento marxista"42.

Pero, como se habrá notado, estos tres ejemplos constituyen algo así como una prueba ex negativo de mi juicio. Dando, pues, un paso más, quiero abordar ahora la documentación positiva de la influencia de la teología de la liberación en la filosofía latinoamericana de nuestros días, recurriendo precisamente al modelo de la filosofía de la liberación.

Ya he señalado que la influencia de la teología de la liberación sobre la filosofía latinoamericana que se irá perfilando en estos años como filosofía de la 
liberación, encuentra sus condiciones preparatorias en ese proceso en el que, como se mostró, la filosofía misma echa las bases para una convergencia en cuestiones de método y de contenidos con la naciente teología de la liberación. Pero, además de estas condiciones objetivas de posible convergencia, se encuentra el hecho decisivo de lo que realmente se puede llamar la "unión personal" por la que se destaca, justo en estos años iniciales de ambos movimientos, la relación existente entre teología y filosofía de la liberación en América Latina. Es, en efecto, un hecho innegable que gran parte de los autores que en estos años van haciendo cristalizar el movimiento de teología de la liberación son los mismos que paralelamente asumen el trabajo de dar el paso definitivo en el proceso de transformación de la filosofía latinoamericana en filosofía de la liberación, al plantearse explícita y sistemáticamente la tarea de constitución de una filosofía de la liberación. Para ver la fuerza de este hecho creo que basta con pensar en nombres como los de Hugo Assmann, Enrique Dussel, Juan Carlos Scannone; pero también en otros que luego se apartan como Julio $\mathrm{C}$. Terán Dutari u otros, que no forman parte del movimiento como tal, pero que contribuyen al desarrollo teórico del mismo en otros años; así, por ejemplo, José P. Miranda, quien significativamente puso a su famoso libro Marx y la Biblia, el subtítulo de Crítica a la filosofía de la opresión $^{4.3}$. Pero igualmente se pueden recordar otros nombres como los de Ignacio Ellacuría y Pedro Trigo, cuyos aportes al movimiento de filosofía de la liberación empiezan a ser explícitos algo más tarde, esto es, alrededor de 1975 y de 1980 respectivamente ${ }^{44}$. Cabe señalar aquí que, como hacen ver los nombres de Dussel, Scannone, Trigo, etc., esa "unión personal" entre teología y filosofía de la liberación ha continuado hasta nuestros días; y que, en ciertos grupos, goza hoy incluso de un marco institucionalizado, como es el caso del "Equipo Jesuita Latinoamericano de Reflexión Filosófica" que, desde su fundación oficial en Quito en 1981, viene reuniéndose periódicamente cada año ${ }^{45}$.

Ha de advertirse, por otra parte, que el destacar el que la filosofía de la liberación es hecha, en parte, por autores que también son teólogos, y, concretamente, teólogos cristianos, no significa que tenga la intención de enfocar el tema en cuestión desde la perspectiva mas amplia y difusa de la influencia del cristianismo en la filosofía latinoamericana de la liberación. No me interesa diluir el tema en un rastreo de la presencia de motivos de pensamiento cristiano en la filosofía de la liberación ${ }^{46}$, sino que, de acuerdo a mi planteamiento inicial, mi interés está en ver precisamente cómo la teología de la liberación (profesional) influye en la filosofía de la liberación a nivel metodológico y sistemático. $O$ sea, que los autores nombrados no representan simplemente "pensadores cristianos" sino que los considero aquí fundamentalmente como protagonistas de la teología de la liberación.

Aunque sea obvio, deseo señalar también que la atención que le dedico a los autores que unen en su propia persona teología y filosofía de la liberación, no supone en modo alguno reducir el movimiento de filosofía de la liberación a la corriente representada por ellos; corriente que es a su vez muy compleja ${ }^{47}$. Es 
cierto que con ello estoy privilegiando una tendencia de este movimiento; pero no entiendo esta opción como reduccionista, porque la tomo en virtud de la fuerza que tiene dicha corriente para ilustrar de modo ejemplar la repercusión de la teología de la liberación en el desarrollo filosófico reciente de América Latina. ${ }^{48}$

Así, pues, me concentraré en la corriente que, como decía, puede ser designada como "filosofía cristiana de la liberación". Los nombres de sus principales representantes ya los he citado: Hugo Assmann, Enrique Dussel, Ignacio Ellacuría, Juan C. Scannone, etc; pero también se podrían incluir otros como Carlos Cullen, Rubén Dri, etc. Por razones evidentes no podré proceder en el análisis de esta corriente haciendo una evaluación de la obra de cada uno de los representantes de la misma. Esto supondría revisar un material bibliográfico que se extiende casi 25 años y en el que se documenta una historia de desarrollo filosófico, sumamente compleja, tanto en la parte biográfica personal de sus agentes como en lo que respecta a la diferenciación de tendencias ${ }^{49}$. Y es evidente, repito, que una evaluación semejante no puede ser emprendida aquí. Así que también en este sentido tengo que hacer una opción, decidiéndome por un planteamiento temático de la cuestión sobre la influencia de la teología de la liberación en el desarrollo de la filosofía de la liberación. Los campos temáticos en los que -independientemente de las tendencias que puedan constatarse en esta corriente del movimiento de la filosofía de la liberación - hay una innegable repercusión de las perspectivas centrales de reflexión que va consolidando la teología de la liberación, pueden resumirse en los siguientes:

-Comprensión de la actividad filosófica: Creo, en efecto, que sin la incidencia de la teología de la liberación no es explicable el giro que se nota en la filosofía latinoamericana en estos años, precisamente en el punto que atañe a la comprensión de sí misma. Es decir, que el impacto de la teología de la liberación en la filosofía se nota primeramente en un proceso de redefinición de ésta última; un proceso por el que la filosofía se empieza a comprender a sí misma como una actividad práctica que no brota de un sentimiento abstracto de admiración sino de una experiencia de afectación por la realidad histórica. Y por eso, ahora se comprende a sí misma como un "saber" que debe responder de y ante el otro de un mundo histórico concreto.

Punto de partida del filosofar: También en este campo opera la filosofía de la liberación un cambio que me parece que es facilitado por los avances de la teología de la liberación en su esclarecimiento de los pobres como lugar hermenéutico. Sobre este trasfondo teológico va viendo el filósofo la necesidad de anclar su reflexión, no en conceplos o en tradiciones conceptuales, sino en tradiciones de acción liberadora, esto es, en la historia de liberación de una comunidad. Y por esta vía también llega la filosofía a concretizar su punto de partida en el sentido de un lugar histórico que exige que su reflexión asuma como perspectiva de arranque la opción por los pobres. 
La función de la filosofía: Como consecuencia de lo anterior, se sigue un cambio en la visión de la función teórica y social de la filosofía. Y me parece que en esto también es decisivo el ejemplo de la teología de la liberación con su énfasis en la dimensión crítica y de denuncia profética que ha de distinguir a toda teología cristiana que no esté viciada ideológica o institucionalmente. En esta teología tiene, pues, la filosofía un paradigma para redescubrir sus mejores tradiciones y redefinir su función en términos de crítica y de desenmascaramiento de los sistemas de conceptos y de prácticas opresores. Dicho en otros términos: la filosofía se comprende como un saber histórico-crítico cuya función primera es la de fomentar con sus medios la liberación del pueblo pobre.

-Inversión de la prioridad de las racionalidades filosóficas: Entiendo por esto, sobre todo, el cambio fundamental que se da en la filosofía de la liberación en el momento en que esta se constituye sobre la experiencia de que lo primero no es la llamada razón teórica sino la razón práctica concreta que busca responder a la cuestión de cómo hacer justicia al otro. Esta priorización de la experiencia ética y sus consecuencias para el trabajo reflexivo de la filosofía me parece que está también en conexión con la repercusión de la teología de la liberación, y especialmente con su esfuerzo por constituirse en la praxis de una fe que reclama, por esencia del misterio divino que la provoca, la salvación de la vida del pobre.

-Transformación de la filosofía en un universo ético: Entiendo esta transformación como el punto donde se condensa la inversión de la prioridad de las racionalidades filosóficas. Esto es, el primado absoluto de la razón práctica lleva a la filosofía de la liberación a transformar todo el quehacer filosófico poniéndolo bajo el criterio imperativo del "libera al pobre". Desde esta perspectiva, debe ser rehecha toda la filosofía. Esta transformación, creo, es igualmente un resultado que la filosofía de la liberación logra con la ayuda de la teología de la liberación. Pienso concretamente en la repercusión de la concretización política -en el mejor sentido del término político- que ha sabido hacer la teología de la liberación del precepto del amor al próximo.

-Comprensión del método: La teología de la liberación, que desde sus inicios empezó preocupándose por cuestiones metodológicas, pasa esta preocupación suya, creo, como una hipoteca que recoge la filosofía de la liberación. Pero lo decisivo no está simplemente en este hecho. Lo decisivo es que la filosofía de la liberación recoge esa hipoteca como necesidad de renovación metodológica en un sentido análogo al que lo ha hecho la teología de la liberación; aceptando así la urgencia de cristalizar su propio discurso en diálogo con las ciencias sociales, pero también con formas de la sabiduría popular, sean éstas ritos, símbolos o creaciones artísticas.

- Comprensión de la historia de la filosofía: Como resultado del proceso que inicia la filosofía de la liberación en los campos temáticos nombrados, obtiene la 
filosofía un nuevo acceso a su propia tradición e historia. Esto marca otro campo temático en el que, creo, el ejemplo de la teologia de la liberación es altamente motivante para la filosofía. Como es sabido, la teología de la liberación es una de las primeras teologías que ha reconocido y practicado lo esencial que es para la teología el hacer historia de la teología; y hacerla precisamente desde la perspectiva del cristianismo liberador. Pues bien, soy de la creencia que este trabajo teológico ha impactado fuertemente la filosofía de la liberación, llevándola a revisar su historia oficial y a preguntarse si la historia de la filosofía latinoamericana se agota en esa historia académica que suelen trasmitir los manuales al uso. O sea, que la reconstrucción que la filosofía latinoamericana hace hoy de su historia desde una perspectiva de liberación se debe, al menos en gran parte, al trabajo que en historia de la teología ha venido y viene desarrollando la teología de la liberación. $\mathrm{Y}$ esto es tanto más importante para la filosofía latinoamericana cuanto que, por esa reconstrucción de su historia, ésta aprende a mantener una relación más libre consigo misma, precisamente porque va aprendiendo que su historia no es únicamente la historia de la tradición académicamente sancionada, sino una historia hecha de muchas historias y de muchas tradiciones. Comprende, en fin, su historia como un complicado tejido de tradiciones.

Pero dejo aquí la evaluación de los campos temáticos en que me parece confirmada la incidencia de la teología de la liberación en la filosofía de la liberación, para pasar sin más al tercero y último punto de mi trabajo.

\section{Esbozo de algunas perspectivas para una interacción más fecunda entre teología de la liberación y filosofía}

Como ya señalé, se trata ahora de utilizar los resultados anteriores como base para formular algunos puntos centrales de lo que podría ser la agenda para un mejor intercambio entre teología de la liberación y filosofía en América Latina. $\mathrm{Y}$ hablo ahora de filosofía sin más, porque parto del pronóstico de que la teología de la liberación, justo a través de su impacto en la filosofía de la liberación, ampliará su repercusión en la cultura filosófica de América Latina en el futuro inmediato. Pues sucede que esta corriente filosófica copotenciada por la teología de la liberación es justo la vertiente de pensamiento más fuerte y consistente que, a nivel filosófico, se desarrolla hoy en América Latina. Esta corriente filosófica es, además, la que ha logrado entrar en diálogo con otras posiciones de la filosofía europea y norteamericana de nuestros días ${ }^{511}$. De modo que la filosofía de la liberación tiene hoy una posición que no permite que se la margine de la discusión filosófica actual. Más aún, y tal es mi pronóstico, esta corriente está llamada, por su posición actual, a servir quizá de eje central en la discusión filosófica del continente ${ }^{51}$; $y$, por eso, pienso que a través de ella, la teología de la liberación (o contenidos desarrollados por ella) estarán cada vez más presentes en la cultura filosófica de América Latina. Pero mi pronóstico también conlleva una implicación que marca justo el punto que quiero tocar en este tercer 
apartado: el diálogo entre teología de la liberación y filosofía en América Latina. Creo que el hecho de que la filosofía de la liberación confronte a otros modelos filosóficos con una cierta carga temática de procedencia teológica, representa a su vez un reto para la teología misma, en cuanto que la coloca ante la necesidad de abrirse más al debate filosófico actual y de forzar sus posibilidades de diálogo con la filosofía. Y si insisto en este punto es porque considero válida todavía una apreciación de Gustavo Gutiérrez, hecha en 1986, cuando, respondiendo a la pregunta por la relación entre teología y filosofía en América Latina constataba: "Se trata de un campo que está todavía por explorar. Creo que se han hecho esfuerzos interesantes en Argentina y México; y también en otros países, aunque de una manera menos articulada. Con todo, pienso que queda mucho por hacer todavía. La cuestión que la filosofía latinoamericana se plantea desde hace ya varios años acerca de la significación de un filosofar determinado por el contexto latinoamericano, es un punto de contacto con la teología que nosotros practicamos. A veces tengo la impresión de que la teología ha podido darse cuenta de esta cuestión y responder ante ella más rápidamente y mejor que la filosofía, acaso debido a su vinculación con los grupos de base... Pero, repito, todavía queda mucho por hacer en este campo"s2.

Partiendo de esta constatación, hay que reconocer entonces que la interacción entre teología de la liberación y filosofía en América Latina es todavía, en buena parte, un programa de trabajo. Por eso he hablado de "agenda para un diálogo" o de "perspectivas para una interacción fecunda". De manera muy esquemática creo que dichas perspectivas podrían sintetizarse en los siguientes puntos:

-Reconsideración crítica conjunta de la perspectiva de la inculturación como hilo conductor para el desarrollo de nuevas formas de racionalidad teológicas y filosóficas.

-Revisión de sus respectivas funciones como formas de saber que, en parte, se desarrollan en el marco de instituciones académicas que suponen una determinada organización cultural del saber, así como un interés social en el uso y la finalización del mismo.

-Fundamentación de la perspectiva de que sus tradiciones son, de hecho, tradiciones que hacen del trato responsable con la realidad el eje de sus respectivos desarrollos; y que, en consecuencia, es en el reto del mundo histórico concreto donde encuentran aquello que les da a ambas qué pensar y la base real que en definitiva debería mediar su diálogo.

-Revisión, como consecuencia de lo anterior, de las fronteras disciplinarias heredadas; no para renunciar a sus respectivas autonomías, ni para negar campos de específica competencia, pero sí para reconfigurar los límites disciplinarios sobre la nueva base de la interacción. 
—Delimitación de campos problemáticos reales como retos para desarrollar una reflexión interdiscursiva que responda mejor a la complejidad de la realidad.

-Asumir la inopia de los empobrecidos de este mundo como uno de esos problemas reales que requieren respuesta común, y desarrollar una ética de la afirmación de la vida de los pobres.

-Fundamentación de la opción por los pobres como eje de los criterios para la crítica radical del sistema civilizador vigente, esto es, como perspectiva de una alternativa de civilización en la que la razón técnico-económica queda supeditada al valor irremontable de la vida de la persona.

-Desarrollar —como consecuencia o concretización de lo anterior —un "plan ético-político" para subvertir la lógica de la exclusión (y su consecuente cierre de las posibilidades de innovación histórica) con una praxis que, siendo capaz de ensanchar el campo de lo posible históricamente, sigue construyendo la historia de la esperanza de la humanidad.

Cabe señalar, para concluir, que, trabajando este programa, la teología de la liberación y la filosofía en América Latina no solamente podrían abrir un nuevo capítulo en la historia de sus relaciones sino que, acaso, lleguen, además, a modelar una nueva figura de intelección interactiva de la realidad latinoamericana.

\section{Notas}

1. Cfr. S. Alcamán, Cosmovisión mapuche, en Servicio 99 (1985) 277-279. W. Amado, Teologia negra, en Estudios 1/2 (1988) 63-79; J. M. Argucdas, Dioses y hombres de Huarochirü, Madrid 1975; A. Ajona Santos, Quetzalcoatl: la historia y el mito, en Cuadernos Hispanoamericanos 310 (1976) 94-123; J. Arreguin, Temas biblicos en la teología nálutuatl, en Diálogo Teológico 13 (1979) 5-25; F. Bcltrán Pcña, Los Muiscas, Bogotá, 1987; H. Clastres, La terre sans mal. Le prophétisme tupiguarani, Paris, 1975; S. Ducan (ed.), Cultura negra y teología, San José, 1986; E, Dussel. Racismo, América Latina negra y teología de la liberación, en Misiones Extranjeras 112/113 (1989) 447462; O. Espin, Evangelización y religiones negras, Rio, 1985; J. Estermann, Andine Philosophie. Ansätze zur Rehabilitierung kolonialisierten Denkens, en Neue Zeitschrift für Missionswissenschaft 50 (1994) 189-205; R. Fornet-Betancourt, Para una filosofia intercultural latinoamericana, San Josć, 1994; R. Kusch, Pensamiento aymara y quechua, en América Indigena 31(1971) 389-396; L. Lujambio, Die implize Theologie in der Nahua-Kultur, en R. Fornet-Betancourt (cd.), Theologien in der Sozial- und Kulturgeschichte Lateinamerikas, Bd. 1, Eichstatt 1992, p. 126-196; B. Meliá, El Guarani. Experiencia religiosa, Asunción, 1991; E. Támcz, Quetzalcoatl y el Dios cristiano, en Pasos 35 (1991) 8-22; A. Wagua, Procesos de inculturación desde la visión indigena, en: Jahrbuch für Kontextuelle Theologien, I (1994) 153-165.

2. Cfr. Pablo Richard (ed.), Historia de la teología en América Latina, San José, 1981; y Raíces de la teología latinoamericana, San José, 1985.

3. Cfr. R. Alves, Theology of Hope, Cleveland, 1969. (El título de la tesis doctoral a que se remonta este libro es todavia más ilustrativo: Towards a theology of Liberation, Princeton, 1968). 
4. Cfr. H. Assmann, Teologia de la liberación, Montevideo, 1970; y Teología desde la praxis de liberación, Salamanca, 1973.

5. Cfr. G. Gutićrrez, Hacia una teología de la liberación, Montevideo, 1969; y Teología de la liberación, Lima, 1971.

6. Juan Bautista Alberdi, Ideas para presidir la confección de un curso de filosofia contemporánea, México, 1978, p. 12. Sobre el contexto, significación y alcance del programa de Alberdi puede verse además: R. Fornet-Betancourt, Juan Bautista Alberdi y la cuestión de la filosofía latinoamericana, en Cuadernos salmantinos de Filosofia XII (1985) 317-333; y Estudios de Filosofia Latinomericana, México, 1992, especialmente el capítulo II: La pregunta por la "filosofia latinoamericana" como problema filosófico, pp. 25-49.

7. Véase por ejemplo: José Carlos Mariátegui, ¿Existe un pensamiento hispanoamericano?, en Obras Completas, Tomo 12, Lima, 1971, pp. 22-26. Conviene señalar, por otra parte, que, precisamente, el nombre de Mariátegui está esencialmente vinculado al esfuerzo por crear un marxismo latinoamericano y que en este sentido representa su obra una manera concreta de responder ante la exigencia programática de Alberdi. Cfr. Raúl Fornet-Betancourt, Ein anderer Marxismus. Die philosophische Rezeption des Marxismus in Lateinamerica, Mainz, 1994; especialmente el capitulo 4, pp. 100-140.

8. Cfr. Arturo Ardao, EI historicismo y la filosofia americana, en Cuadernos Americanos 4 (1946) 101-113; Risieri Frondizi, ¿Hay una filosofía iberoamericana?, en Realidad 3 (1948) 158-170; José Gaos, El pensamiento hispanoamericano, Mexico, 1944; y Leopoldo Zea, En torno a una filosofia americana, en Cuadernos Americanos 3 (1942) 63-78.

9. Sociedad Cubana de Filosofia (Ed.), Conversaciones Filosóficas Interamericanas, La Habana, 1953; así como R. Fornet-Betancourt, Problemas actuales de la Filosofia en Hispanoamérica, Buenos Aires, 1985; especialmente el Capitulo 1: El problema de la existencia o no existencia de una filosofía hispanoamericana, pp. 7-28.

10. Augusto Salazar Bondy, Entre Escila y Caribdis. Reflexiones sobre la vida peruana, Lima, 1969, p. 60.

11. Cfr. Augusto Salazar Bondy, Perí Problema, Lima, 1968.

12. Augusto Salazar Bondy, Entre Escila y Caribdis. Reflexiones sobre la vida peruana, ed. cit.; p. 47. Subrayado en el original.

13. Cfr. Augusto Salazar Bondy, ibídem; pp. 55 y ss.; así como su libro póstumo, Educación y Cultura, Buenos Aires, 1979.

14. Augusto Salazar Bondy, ¿Existe una filosofia de nuestra América?, México, 1968, p. 119.

15. Augusto Salazar Bondy, Ibídem, p. 127.

16. Augusto Salazar Bondy, Ibídem, p. 125.

17. Augusto Salazar Bondy, Ibídem, p. 126.

18. Augusto Salazar Bondy, Ibídem, p. 126.

19. Augusto Salazar Bondy, Educación y Cultura, ed. cit.; p. 15 y ss.

20. Cfr. A. Salazar Bondy / L. Zea/ J. C. Terán/ F. Schwartzmann, América Latina: Filosofia y liberación. Simposio de filosofia latinomericana, Buenos Aires, 1974, p. 8, donde expone: "...orientemos el trabajo de nuestro filosofar, clara y decididamente, en el sentido de tratar de cancelar la dominación de nuestros países, con lo que ella implica de dominación interior y exterior; o sea, en el sentido de lo que se puede llamar una filosofía de la liberación, que es lo opuesto a la filosofía de la dominación". 
21. Augusto Salazar Bondy: ¿Existe una filosofía de muestra América?, cd. cit.; p. 133. Para el estudio de la relación de Salazar Bondy con el movimicnto de la filosofía de la liberación en general pucde verse: M. T. Vila Bormey/F. Valdés Garcia, La filosofía de la liberación en Peri, en P. Guadarrama (dircctor), Humanismo y filosofia de la liberación en América Latina, Bogotá, 1993, pp. 21-29; y David Sobrcvilla, Repensando la tradición nacional, Vol. 2, Lima, 1989, pp. 384 y ss.

22. Leopoldo Zea, La filosofía americana como filosofia sin más, México, 1969; p. 153.

23. Leopoldo Zea, Ibídem; p. 153.

24. Leopoldo Zea, Ibídem, p. 153.

25. Leopoldo Zea, Ibídem; p. 160.

26. Cfr. Leopoldo Zea, La filosofía latinoamericana como filosofia de la liberación, en A. Salazar Bondy y otros, América Latina: Filosofia y Liberación, ed. cit.; pp. 10 y ss. Interesante es notar que en esta reformulación que hace ahora Zea de la cuestión por la filosofía latinoamericana hay dos influencias particularmente notorias. Me refiero, por una parte, a la influencia de Jean-Paul Sartre —especialmente del Sartre crítico del colonialismo y del curocentrismo- y, por otra, a la de Frantz Fanon, sobrc todo con su libro - prologado por Sartre - Los condenados de la tierra, publicado en 1963 en México. Y para todo el movimiento que se va gestando no se puede dejar de mencionar la influencia de $\mathrm{H}$. Marcuse cuyo An essay on Liberation se traducc y publica en México en 1969.

27. Cfr. Enrique Dussel, Metafisica del sujeto y liberación, en E. Dussel, Historia de la filosofía y filosofía de la liberación, Bogotá, 1994, pp. 315 y ss.

28. Para esto puede consultarse el documentado panorama que ofrece el estudio de Enrique Dussel, Hinweise zur Entstehung der Befreiungstheologie: 1952-1972, en R. Fornet-Betancourt (Ed.), Theologien in der Sozial- und Kulturgeschichte Lateinainerikas. Die Perspektive der Armen, tomo 3, Eichstatt, 1993. Y, por supuesto, el trabajo ya clásico de Roberto Oliveros Maqueo, Liberación y teología. Génesis y crecimicnto de una reflexión (1966-1976), Lima, 1977, pp. 302 y ss.

29. La confirmación de esta tendencia en todo el movimiento inicial de la tcología de la liberación se evidencia en cl análisis que hace Samucl Silva Gotay en su importante obra: El pensamiento cristiano revolucionario en América Latina y el Caribe, Pucrto Rico, 1981, especialmente pp. 29-72.

30. Jürgen Moltmann, Brief an .José Minguez Bonino, en Evangelische Kommentare 9 (1976), p.756. Recientemente ha retomado esta crítica Reincrio Arce. Cfr. su libro Religion: Poesie der kommenden Welt. Theologische Implikationen im Werk José Martís, Aachen 1993, especialmente pp. 1 y ss.

31. Juan Luis Segundo, Condicionamientos actuales de la reflexión teológica en Latinoamérica, en Encuentro Latinoamericano de Teologia, Liberación y cautiverio, Mexico, 1975, p. 93.

32. Juan Luis Segundo, Ibidem; pp. 94-95.

33. Debo anotar que en esto radica para mi una de las razones por las cuales la primera teología de la liberación no tiene, de hecho, acceso ninguno, ni a la problemática indigena ni a la afroamericana. Ver sobre esto las tempranas advertencias de Luis González (Antropología y teología de la liberación) y de Mardonio Morales (Teología y mundo indígena) en Encuentro Latinoamericano de Teología, Liberación y cautiverio, ed. cit.; pp. 309-316 y 317-318, respectivamente.

34. Hugo Assmann, Teologia desde la praxis de la liberación, Salamanca, 1973, p. 52. 
35. Roberto Oliveros, op. cit.; p. 109. Interesante es recordar que Ellacuria, justo al analizar las diferencias entre un modelo de teología europeo y otro latinoamericano, destacaba: "La referencia a las ciencias sociales como elemento integrante de la labor teológica es bien explícita en un modelo y está prácticamente ausente en el otro. Lo que hay en éste de mediación, en algún modo filosófica, es en el otro fundamentalmente sociológica". Ignacio Ellacuría, Hacia una fundamentación filosófica del método teológico latinoamericano, en Encuentro Latinoamericano de Teología, Liberación y cautiverio, ed. cit.; p. 619.

36. Debe anotarse además que la recepción del marxismo occidental y, en particular, de la teoría critica de la Escuela de Francfort sucede en términos sumamente vagos. Cfr. Martin Traine, Die Sehnsucht nach dem ganz Anderen. Die Frankfurter Schule und Lateinamerika, Aachen, 1994; especialmente pp. 191 y ss.; y pp. 251 y ss.

37. Enrique Dussel, Metafísica del sujeto y liberación, ed. cit.; p. 319.

38. Cfr. Sociedad Católica Mexicana de Filosofía (Ed.), El humanismo y la metafísica cristiana en la actualidad. Actas del Segundo Congreso Mundial de Filosofía Cristiana, Monterrey, 1986; Asociación Católica Ecuatoriana de Filosofía (Ed.), El ateismo actual y la trascendencia divina. Actas del III Congreso Mundial de Filosofía Cristiana, Quito, 1990. Ver también: A. Basave Fernández del Valle, Zur Situation der christlichen Philosophie in Lateinamerika; en R. Fornet-Betancourt (Ed.), Positionen Lateinamerikas, Francfort, 1988, pp. 11-222.

Pero también en la obra de otros representantes de la filosofía cristiana tradicional que no atacan a la teología de la liberación, se hace notoria la falta de incidencia en ellos. Ver, por ejemplo, Rubén José Sanabria, Historia del hombre, México, 1987; y Rubén Sanabria/Mauricio Beachot, Historia de la filosofia cristiana en México, México, 1994; donde se silencia por completo el tema.

39. Cfr. J. J. E. Gracia/E. Rabossi/E. Villanueva/M. Dascal (Eds.), El análisis filosófico en América Latina, México, 1985; E. Bulygin/E. Garzón Valdés (Eds.), Argentinische Rechtstheorie und Rechtsphilosophie heute, Berlín, 1987; y L. Tovar González, Filosofía de la ciencia y análisis filosófico, en Germán Marquinez y otros, La Filosofia en América Latina, Bogotá, 1993, pp. 301-308.

40. Mario Bunge, Filosofia, ciencia, politica, en Concordia. Internationale Zeitschrift für Philosophie 10 (1986) p. 108.

41. Cfr. Agustín Cueva, El marxismo latinoamericano: Historia y problemas actuales, en Tareas 65 (1987) 57-74; Adolfo Sánchez Vázquez, El marxismo en América Latina, en Dialéctica 19 (1988) 11-28. Para aspectos más puntuales, ver además: Pablo Guadarrama, Marxismo y Antimarxismo en América Latina, Bogotá, 1990; Francisco León Tejera y otros, Recepción del marxismo en Enrique Dussel, en Islas 90 (1988) 98-104; Fabio R. Torrado, La teología de la liberación y su manipulación por el Vaticano, en Revista de Ciencias Sociales 13 (1987) 150-167; y Gabriel Vargas Lozano, Marx en Amérique Latine, en Actuel Marx 1 (1987) 133-139.

42. Alejandro Serrano Caldera, Marxisme et christianisme au Nicaragua, en Concordia. Internationale Zeitschrift für Philosophie 7 (1985) p.83. Para el caso concreto de la relación entre marxismo y teología de la liberación en Nicaragua, ver también: Giulio Girardi, Fe en la revolución. Revolución en la cultura, Managua, 1983; y Sandinismo, marxismo, cristianismo en la Nueva Nicaragua, Managua, 1989. Y, para el caso también ejemplar de Cuba, ver su obra: Cuba, después del derrumbe del comunismo, Madrid, 1994. Debe quedar anotado igualmente que Ignacio Ellacuría esbozó 
una especie de catálogo de los puntos en que la tcología de la libcración podía enriquecer a la teoría marxista. Cfr. Ignacio Ellacuria, Theologie der Befreiung und Marxismus, en Peter Rottlander (Ed.), Theologie der Befreiung und Marxismus, Münster 1986, pp.77-108. Ver tambićn cl númcro monográfico Marxismo y teologia de la liberación de la revista Cristianismo y Sociedad 98 (1988), del que cabc destacar los estudios de Enrique Dussel, Michacl Löwy, Otto Maduro y Orlando Millas.

43. Cfr. José P. Miranda, Marx y la Biblia, Salamanca, 1972.

44. En el caso de Ignacio Ellacuría habría que tener presente, sin embargo, que su aporte tanto a la tcología de la libcración como a la filosofía de la libcración va tomando cuerpo desde los primcros momentos, como lo documentan, cntre otros, los siguientes estudios: Progreso, Revolución, en ECA 25 (1970) 152-154; Teología de la revolución y Evangelio, en ECA 25 (1970) 581-584; Liberación: Misión y carisma de la iglesia latinoamericana, en ECA 26 (1971) 61-80; y Filosofía y política, en ECA 27 (1972) 373-386. Con todo, creo que 1975 pucde valer como el año cn que su aporte gana ya un peso específico con trabajos como: Hacia una fundamentación filosófica del método teológico latinoamericano, en ECA 30 (1975) 409-425; y Tesis sobre posibilidad, necesidad y sentido de una teologia latinoamericana, en A. Vargas Machuca (ed.), Teologia y mundo contemporáneo: homenaje a Karl Rahner, Madrid, 1975, pp. 325-350. Es, además, en estos trabajos donde, en lo que sc refiere a lo filosófico, se esboza la línea de reflexión de fondo que culminará años más tarde en importantes aportcs a una filosofía de la liberación latinoamericana. Mencionaré aquí sólo dos: Función liberadora de la filosofía, en ECA 40 (1985) 45-64; y la obra póstuma: Filosofía de la realidad histórica, San Salvador, 1990.

45. Cfr. Ignacio Ellacuría/Juan C. Scannone (compiladores), Para una filosofía desde América Latina, Bogotá, 1992; y Juan C. Scannone/M. Perine (compiladores), Irrupción del pobre y quehacer filosófico, Buenos Aires, 1993.

46. Cfr. Julio Terán Dutari, La presencia del pensamiento cristiano en la filosofía latinoamericana de la liberación, en A. Salazar Bondy/L. Zea y otros, América Latina: Filosofía y Liberación, ed. cit.; pp. 25-31.

47. Se sabe que incluso dentro de lo que se podría llamar la "filosofía cristiana de la liberación" hay varias tendencias. Ver sobre csto: M. Domínguez Miranda, Christliche, nicht-scholastische Philosophie in Lateinamerika, cn: E. Coreth y otros (ed.), Christliche Philosophie im katholischen Denken des 19. und 20. Jahrhunderts, Tomo 3: Moderne Strömungen im 20. Jahrhundert, Graz-Wien-Köln, 1990, especialmente pp. 713 y ss.; y Enrique Dussel, La filosofía en América Latina en el siglo $X X$ (manuscrito). Por lo que hace al movimiento en general, es conocida también su amplitud teórica, pues recoge hoy posiciones que van desde las de Leopoldo Zca hasta Arturo A. Roig pasando por la de Francisco M. Quesada, sin ignorar el reciente desarrollo de una corriente desde el marxismo clásico en el grupo cubano de pensamiento latinoamericano coordinado por Pablo Guadarrama.

48. Pero tampoco quiero ocultar que en otras corrientes de la filosofía de la liberación reina todavía un fuerte recelo frente a todo lo que pueda parecer una influencia teológica; y que algunos representantes ponen de manifiesto incluso un tono agresivo y polémico al referirse al tema. Ver, por ejemplo, Horacio Ccrutti, Filosofía de la liberación latinoamericana, México, 1983; y su artículo La recepción del marxismo por el pensamiento cristiano latinoamericano, en Dialéctica 19 (1988) 77-83; así 
como Arturo A. Roig, Rostro y filosofía de América Latina, Mendoza, 1993, especialmente pp. 203 y ss.; y también Francisco Miró Quesada, Tres momentos y un epílogo, en Revista Teológica Limense 27 (1993) 282-316; y José M. García Madariaga, En torno al "ateísmo auténtico". (Respuesta a un artículo de Francisco Miró Quesada), en Revista Teológica Limense 27 (1993) 462-475.

49. Como ilustración de este material bibliográfico cuyo análisis detenido excedería con mucho las posibilidades de este estudio, cabe citar: H. Assmann, Presupuestos políticos de una filosofía latinoamericana, en Nuevo Mundo 1 (1973) 25-35; Crítica á lógica da exclusāo, Sāo Paulo, 1994; E. Dussel, Para una ética de la liberación latinoamericana, Tomos 1-5, Buenos Aires - México - Bogotá, 1973-1980; Filosofía de la liberación, México, 1977; Praxis latinoamericana y filosofía de la liberación, Bogotá, 1983; Las metáforas teológicas de Marx, Estella (Navarra) 1993; Apel, Ricoeur, Rorty y la filosofia de la liberación, México, 1993; y Debate en torno a la ética del discurso de Apel, México, 1994; I. Ellacuría, El objeto de la filosofía, en ECA 36 (1981) 963-980; Teología de la liberación y marxismo, en Revista Latinoamericana de Teología 20 (1990) 109-136; y Filosofía Latinoamericana, en J. C. Scannone/M. Perine (compiladores), op. cit.; pp. 163-181; Juan Scannone, Ontología del proceso auténticamente liberador, en Stromata 1/2 (1972) 107-150; Teología de la liberación y praxis popular, Salamanca, 1976; Sabiduria, filosofía e inculturación, en Stromata $3 / 4$ (1982) 317-327; Sabiduria popular, símbolo y filosofia, Buenos Aires, 1984; Nuevo punto de partida de la filosofia latinoamericana, Buenos Aires, 1990; y Weisheit und Befreiung, Düsseldorf, 1992; C. Cullen, El descubrimiento de la nación y la liberación de la filosofia, en Nuevo Mundo 1 (1973) 90-102; Fenomenología de la crisis moral, Buenos Aires, 1978; y Reflexiones desde América, 3 tomos, Buenos Aires, 1986-1987; Rubén Dri, Teología y dominación, Buenos Aires, 1987; Razón y Libertad, Buenos Aires, 1994.; Intersubjetividad y reino de la verdad, Buenos Aires, 1993, y también habría que considerar aquí algunas obras de Franz J. Hinkelammert, por ejemplo, Crítica a la razón utópica, San José, 1984; Las armas ideológicas de la muerte, San José, 1977; asi como sus trabajos en el marco del programa de diálogo entre la ética del discurso y la ćtica de la libcración. Sobre esto, ver: R. Fornet-Betancourt (ed.), Ethik und Befreiung, Aachen, 1990; Diskursethik oder Beireiangsethik, Aachen, 1992; Die Diskursethik und ihre lateinamerikanische Kritik, Aachen, 1993; y Konvergenz oder Divergenz. Eine Bilanz des Gesprächs zwischen Diskursethik und Beiretungsethik, Aachen, 1994.

50. Cfr. K-O- Apel/E. Dussel/R. Fornet-Betancourt, Fundación de la ética y filosofía de la liberación, México, 1992; Filosofía e liberazione. La sfida del pensiero del Terzo Mondo, el número monográfico de Segni e Comprensione 15 (1992); E. Dussel, Apel, Ricoeur, Rorty y la filosofía de la liberación, México, 1993, E. Dussel (compilador), Debate en torno a la ética del discurso de Apel, México, 1994, y M. Moreno Villa, Filosofía de la Liberación y Personalismo, Murcia, 1993.

51. Caso con carácter ejemplar de cste nuevo proceso es la discusión de la filosofía de la liberación por represcntantes del marxismo cubano. Cfr. Pablo Guadarrama (dircctor), Humanismo y filosofia de la liberación en América Latina, La Habana, 1991.

52. Gustavo Gutiérrez, Action et contemplation dans la théologie de la libération. Entretien, en Concordia, Internationale Zeitschrift für Philosophie 12 (1988) p. 71. 